\title{
Adição da proteína específica do oviduto de porcas (pOSP) e da melatonina em meios de maturação e o efeito na clivagem in vitro de embriões suínos
}

\author{
[Addition of the oviduct specific protein of porcine ( $p O S P$ ) and melatonin in maturation media and their \\ effect on the in vitro production of pig embryos] \\ T.S. Kawamoto ${ }^{1}$, L.S. Amorim ${ }^{2}$, L.L. Oliveira ${ }^{1}$, H.H. Shiomi ${ }^{1}$, \\ E.P. Costa ${ }^{1}$, J.D. Guimarães ${ }^{1}$ \\ ${ }^{1}$ Universidade Federal de Viçosa - Viçosa, MG \\ ${ }^{2}$ Biotran - Alfenas, MG \\ RESUMO
}

\begin{abstract}
No presente estudo, utilizou-se a melatonina e a proteína específica do oviduto (pOSP) nos meios de maturação in vitro. Foram avaliadas a expansão do complexo cumulus-ovócito (CCOs), as concentrações intracelulares de espécies reativas de oxigênio (ROS) e o desenvolvimento embrionário nos diferentes grupos $(\mathrm{C}=$ controle; $\mathrm{T} 1=$ somente com melatonina; $\mathrm{T} 2=$ com melatonina e pOSP e $\mathrm{T} 3$ somente com pOSP). No tocante à expansão do CCOs, houve diferença $(\mathrm{P}<0,05)$ dos valores obtidos no grupo $\mathrm{C}$ em relação aos valores médios dos grupos T1, T2 e T3, porém não houve diferença entre os valores obtidos nos tratamentos $(\mathrm{P}>0,05)$. Na dosagem de ROS, não houve diferença entre os valores médios obtidos no grupo C $(26,4 \pm 10,9)$ e o valor verificado no grupo T1 $(23,4 \pm 7,8)$, porém no grupo T2 $(21,3 \pm 9,7)$ o valor médio mostrou-se satisfatório em relação ao valor do grupo C. No entanto, o valor médio do grupo T3 $(16,6 \pm 10,5)$ foi o que demonstrou resultado mais satisfatório quando comparado aos demais grupos $(\mathrm{P}<0,05)$. A produção de embriões foi avaliada por meio da taxa de clivagem. Não houve diferença $(\mathrm{P}>0,05)$ entre os valores obtidos entre o grupo $\mathrm{C}(48,9 \%)$ e os valores verificados nos grupos T1 $(51,5$ $\%)$, T2 (50\%), T3 (57,7\%), nem destes entre si. Este estudo permitiu concluir que a proteína específica do oviduto recombinante e a melatonina foram eficientes em melhorar a expansão dos CCOs. Além disso, as células tratadas com pOSP mostraram-se com menor quantidade de ROS, podendo a pOSP ser considerada um antioxidante proteico.
\end{abstract}

Palavras-chave: suíno, produção in vitro de embriões, proteína específica do oviduto, melatonina, antioxidante

\begin{abstract}
The present study used melatonin and recombinant oviduct specific protein (pOSP) in in vitro maturation medium (IVM). The expansion of the cumulus-oocyte complexes (COCs), the intracellular concentrations of reactive oxygen species (ROS) and embryo development of the different groups were evaluated $(C=$ control; $T 1=$ melatonin; $T 2=$ melatonin and pOSP and T3 = pOSP). Regarding the COCs expansion, the groups T1, T2 and T3 showed satisfactory results compared with group $C(P<0.05)$, but there was no difference between treatments $(P>0.05)$. In the ROS dosage, there was no difference between the mean values obtained in group $C$ (26.4 \pm 10.9$)$ and group 1 (23.4 \pm 7.8$)$. However, in group 2 (21.3 \pm 9.7$)$, the average value was found to be satisfactory in relation group $C$. Despite that, the average value of treatment $3(16.6 \pm 10.5)$ was the most satisfactory result found compared to the other groups $(P<0.05)$. The production of embryos was evaluated by cleavage rate, there was no difference between the values obtained in group $C$ and the values recorded in groups T1 (51.5\%), T2 (50\%), T3 (57.7\%), and among them. This study showed that the pOSP and the melatonin were effective in the improvement of the expansion of COCs cells. In addition, the cells that were treated with pOSP presented a lower amount of ROS, allowing the pOSP to be considered a proteic antioxidant.
\end{abstract}

Keywords: porcine, in vitro production of embryos, oviduct specific protein, melatonin, antioxidant

Recebido em 16 de julho de 2015

Aceito em 18 de fevereiro de 2016

E-mail: taynan.kawamoto@ufv.br 


\section{INTRODUÇÃO}

No intuito de aumentar a produção in vitro de embriões, diversas substâncias têm sido utilizadas ao longo de vários anos. Entre essas, encontram-se os antioxidantes, utilizados para neutralizar as espécies reativas de oxigênio (ROS), como o superóxido dismutase (SOD), a catalase e a glutationa peroxidase. Além destes, ainda há os antioxidantes proteicos (ex.: melatonina), as vitaminas, os flavonoides e os quelantes de metais $\left(\mathrm{Cu}^{+2} \mathrm{e} \mathrm{Fe}^{+2 /+3}\right)$ (Cetica et al., 2001; Takahashi, 2012; Agarwal et al., 2014). Em suínos, houve a diminuição da fragmentação de DNA em blastocistos que derivaram de ovócitos, os quais foram maturados em meio com suplementação de melatonina, quando comparados aos ovócitos que foram maturados em meio sem a suplementação de melatonina (Do et al., 2015), sugerindo que a melatonina tem função regulatória no desenvolvimento de ovócitos e embriões. Em búfalas, a suplementação com melatonina nos meios de maturação melhorou a taxa de maturação nuclear de ovócitos, reduziu o estresse oxidativo, a peroxidação de lipídeos e os danos ao DNA (Manjunatha et al., 2009). Além destes antioxidantes, novas substâncias vêm sendo estudadas no intuito de serem utilizadas como tais.

Nos estudos de Shi et al. (2009), os autores verificaram que a melatonina no fluido folicular de suínos apresentava concentração de $10^{-11} \mathrm{M}$, sugerindo que a melatonina tem importante papel na maturação in vivo. Os autores adicionaram melatonina no meio de maturação in vitro de suínos e observaram que a melhor concentração, que aumentou o número de ovócitos maturados $\mathrm{e}$ melhorou o desenvolvimento de embriões in vitro, foi de $10^{-9} \mathrm{M}$. Já em outro experimento, suplementações superiores a $4 \times 10^{-8} \mathrm{M}$ de melatonina durante a maturação in vitro de ovócitos de suínos resultou em maior percentual de ovócitos com extrusão do corpúsculo polar e uma porcentagem maior de ovócitos ativados partenogeneticamente desenvolvidos até blastocistos (Kang et al., 2009).

$\mathrm{O}$ oviduto fornece um ambiente adequado para maturação ovocitária, capacitação espermática, fecundação e desenvolvimento embrionário inicial (Miessen et al., 2011). Isso ocorre devido a mudanças bioquímicas e fisiológicas oriundas da ação hormonal durante os diferentes períodos do ciclo estral. Dessa maneira, proteínas e outras substâncias presentes nesse ambiente poderiam ter efeitos positivos na maturação de ovócitos suínos, inclusive na diminuição de ROS.

Nos estudos de Kouba et al. (2000), as concentrações de glicoproteína específica do oviduto de porcas (pOSP) de $10-100 \mu \mathrm{g} / \mathrm{mL}$ diminuiu a polispermia quando se comparou com o controle (24-29 versus 61\%). Em concordância com os autores, Romar et al. (2015) verificaram que a adição de pOSP ao meio de fecundação reduziu a incidência de polispermia em $40 \%$, além de diminuir o número de espermatozoides ligados ao ovócito, e aumentou a taxa de blastocistos. Além do benefício da adição da pOSP no meio de FIV, houve também melhora na produção in vitro de embriões com a utilização da pOSP quando esta foi adicionada horas antes da fecundação (McCauley et al., 2003; Coy et al., 2008; Mondejar et al., 2013). Entretanto, Cebrian-Serrano et al. (2013) não observaram diminuição da polispermia nem melhora na taxa de clivagem, porém observaram maior expressão de genes relacionados com a melhor qualidade embrionária em embriões bovinos que tiveram seus ovócitos tratados com fluido do oviduto.

Apesar de a pOSP ser utilizada com o intuito de diminuir as taxas de polispermia, vários estudos são necessários a fim de avaliar se há outros benefícios da proteína que poderiam estar relacionados com a maturação do ovócito, uma vez que o oviduto fornece ambiente adequado para tal e, no período do estro, a fêmea apresenta uma maior expressão da pOSP (Buhi, 2002), mostrando que a proteína poderia estar associada com modificações nos ovócitos.

Assim, este trabalho tem como objetivo melhorar a maturação in vitro de ovócitos de suínos, por meio da diminuição dos níveis de ROS. Para isso, tentou-se mimetizar as condições que ocorrem in vivo, por meio da adição de melatonina durante todo o período de maturação, já que esta existe fisiologicamente no fluido folicular, e da adição de pOSP nas últimas quatro horas do período de maturação ovocitária. Isso porque a pOSP adicionada horas antes da fecundação melhorou o processo de produção in vitro de embriões (McCauley et al., 2003; Coy et al., 2008; Mondejar et al., 2013). 


\section{MATERIAL E MÉTODOS}

Todos os procedimentos relativos à manipulação de animais e às amostras biológicas foram realizados de acordo com as normas para uso de animais em experimentação e aprovados pelo Comitê de Ética da UFV, sob número 19/2014.

Todos os reagentes usados neste experimento foram adquiridos da Sigma-Aldrich Química S.A. (São Paulo, SP, Brasil). Quando não, estes foram citados.

Para a produção da pOSP, foi adquirido um plasmídeo, da empresa Gen Script ${ }^{\circledR}$ (New Jersey, USA). A sequência foi recuperada pela base de dados de nucleotídeos e proteínas do GenBank (U43490). Este plasmídeo foi inserido em células E. coli competentes para estas sintetizarem e expressarem a proteína que posteriormente foi recuperada em coluna de níquel. O conteúdo total da proteína foi determinado pelo método de Bradford utilizando padrão de BSA. As alíquotas foram armazenadas a $-20^{\circ} \mathrm{C}$ até serem utilizadas (dados não publicados).

O meio de maturação in vitro (MIV) utilizado foi o North Carolina State University 23 (NCSU 23) (Petters e Wells, 1993) suplementado com 10\% de fluido folicular suíno (v:v), $10 \mathrm{mg} / \mathrm{mL}$ de EGF, 10UI/mL de hCG (Vetecor ${ }^{\circledR}$, Hertape Calier, Brasil), 10UI/mL de eCG (Folligon ${ }^{\circledR}$, MSD Saúde Animal, Brasil) e $0,1 \mathrm{mg} / \mathrm{mL}$ de cisteína, nas primeiras 22 horas. Nas 22 horas seguintes, os ovócitos foram colocados em meio NCSU 23 sem suplementação hormonal. O fluido folicular foi obtido conforme descrito por Kwak et al. (2012).

O meio de fecundação in vitro (FIV) utilizado foi Tris Buffered Medium modificado - TBMm (Abeydeera e Day, 1997). Os embriões foram cultivados em NCSU 23, suplementados com $4 \mathrm{mg} / \mathrm{mL}$ de BSA (albumina sérica bovina, fração 5), $0,17 \mathrm{mM}$ de piruvato de sódio, $2,73 \mathrm{mM}$ de lactato de sódio e $50 \mu \mathrm{g} / \mathrm{mL}$ de gentamicina (GIBCO ${ }^{\circledR}$, Invitrogen, Brasil). Às 72 horas após a fecundação, todos os embriões clivados foram transferidos para novo meio de cultivo NCSU 23, suplementado com $4 \mathrm{mg} / \mathrm{mL}$ de BSA, $50 \mu \mathrm{g} / \mathrm{mL}$ de gentamicina e $5,5 \mathrm{mM}$ de glicose (Wongsrikeao et al., 2006). Os meios MIV, FIV, e CIV foram cobertos com óleo mineral e equilibrados a $39^{\circ} \mathrm{C}$ com $5 \%$ de $\mathrm{CO}_{2}$ em $95 \%$ de ar umidificado, por, pelo menos, $12 \mathrm{~h}$ antes da utilização (Kouba et al., 2000).

Os ovários foram obtidos em frigorífico e armazenados, para transporte, em garrafa térmica contendo solução salina $0,9 \%$ autoclavada e acrescida de $10 \mathrm{mg} / \mathrm{mL}$ de gentamicina, mantidos em temperatura de $32^{\circ} \mathrm{C}$ (Kwak et al., 2012). No limite máximo de duas horas após o abate, os ovócitos foram aspirados de folículos antrais (3$6 \mathrm{~mm}$ de diâmetro) usando agulhas de $18 \mathrm{G}$ acopladas a seringas de $10 \mathrm{~mL}$. Os ovócitos foram rastreados em solução de PBS adicionado de vermelho de fenol $(0,01 \mathrm{~g} / \mathrm{L})$ e álcool polivinílico (PVA; $0,01 \%)$ a $39^{\circ} \mathrm{C}$. Os ovócitos foram selecionados de acordo com Kwak et al. (2012), sendo considerados os ovócitos com citoplasma homogêneo e com mais de três camadas de cumulus oophorus compacto (grau I). Em seguida, os ovócitos foram lavados três vezes em meio NCSU 23 suplementado, e 30 ovócitos foram dispostos em gotas de maturação de $200 \mu \mathrm{L}$ e separados em quatro grupos:

grupo C: meio MIV sem suplementação de melatonina e/ou pOSP durante as 44 horas de maturação (sem adição de melatonina e/ou pOSP nos dois meios de MIV);

grupo T1: suplementação de $10^{-9} \mathrm{M}$ de melatonina (Shi et al., 2009) no meio de MIV durante as 44 horas de maturação (adição de melatonina nos dois meios de MIV);

grupo T2: adição de $10^{-9} \mathrm{M}$ de melatonina no meio de MIV durante as 44 horas de maturação (adição de melatonina nos dois meios de MIV) e adição de $10 \mu \mathrm{g} / \mathrm{mL}$ (Kouba et al., 2000) de pOSP na gota de $200 \mu \mathrm{L}$ de meio MIV durante as quatro horas finais da maturação (adição de pOSP na gota do segundo meio de MIV);

grupo T3: adição de $10 \mu \mathrm{g} / \mathrm{mL}$ (Kouba et al., 2000) de pOSP na gota de $200 \mu \mathrm{L}$ de meio MIV durante as quatro horas finais da maturação (adição de pOSP na gota do segundo meio de MIV).

A avaliação da expansão das células do CCOs foi realizada 44 horas após a MIV, conforme Gomez et al. (2012): zero = sem expansão das células do CCOs; 1 = mínimo de resposta observável; $2=$ expansão das camadas mais externas do CCOs; 3 = expansão de todas as camadas, exceto a corona radiata e $4=$ expansão de todas as camadas do CCOs. As células avaliadas como 3 e 4 foram consideradas como tendo a melhor expansão do 
CCOs. Foram realizadas quatro repetições, sendo observados aproximadamente 52 ovócitos em cada grupo experimental a cada repetição.

A concentração de ROS nos ovócitos foi determinada de acordo com o método de diacetato de diclorofluoresceína (DCFDA) descrito por Hashimoto et al. (2000). Após a $\mathrm{MIV}$, os ovócitos maturados foram transferidos para o meio de cultivo contendo $10 \mu \mathrm{M}$ de DCFDA e mantidos por 30 minutos em abrigo de luz a $37^{\circ} \mathrm{C}$. Em seguida, foram lavados em PBS com $0,1 \%$ de PVA e colocados em gotas de $10 \mu \mathrm{L}$ para serem avaliados sob microscópio de varredura a laser confocal Zeiss LSM 510 Meta (Zeiss GmbH, Jena, Alemanha), com excitação de $480 \mathrm{~nm}$ e emissão de $510 \mathrm{~nm}$. As imagens foram obtidas com objetiva de $10 \mathrm{x}$ e cortes seriados de $1,9 \mu \mathrm{m}$ para cada ovócito. A fluorescência foi mensurada por conversão do número de pixels para imagens em escala de cinza usando-se o software Image J. Foram realizadas quatro repetições, sendo observados aproximadamente 10 ovócitos em cada grupo experimental a cada repetição

Após 44 horas de maturação, os CCOs tiveram as células do cumulus removidas com adição de $0,1 \%$ de hialuronidase no meio de maturação e foram vorterizados por um minuto; posteriormente, foram lavados três vezes em meio Tris Buffered Medium modificado (TBMm) e depois transferidos para ele, previamente equilibrado à temperatura de $39^{\circ} \mathrm{C}$.

O sêmen para a FIV foi obtido de um único macho, durante todo o experimento, pela técnica de mão enluvada, sendo utilizada somente a fração rica. Posteriormente, ele foi diluído em BTS (Beltsville Thawing Solution, Minitub, Porto Alegre, RS, Brasil) 1:1 e resfriado a $15^{\circ} \mathrm{C}$. Vinte e quatro horas após a coleta, o sêmen foi utilizado.

No dia da FIV, $10 \mathrm{~mL}$ de sêmen resfriado foi aquecido a $37^{\circ} \mathrm{C}$ por cinco minutos. Em seguida, $100 \mu \mathrm{L}$ do sêmen foi colocado delicadamente em $4 \mathrm{~mL}$ de PBS contendo $1 \mathrm{mg} / \mathrm{mL}$ de BSA, $75 \mu \mathrm{g} / \mathrm{mL}$ de penicilina e $50 \mu \mathrm{g} / \mathrm{mL}$ de estreptomicina ( $\mathrm{pH}$ 7.2) e centrifugado três vezes por seis minutos, a 1000G. Após a centrifugação, ressuspendeu-se o pélete em $1000 \mu \mathrm{L}$ de TBMm e a concentração foi determinada por meio da câmara de Neubauer. Para a fecundação dos ovócitos, utilizou-se a concentração de 300.000 espermatozoides/mL (McCauley et al., 2003) para gotas com, no máximo, 30 ovócitos. Transcorridas as seis horas de fecundação, os possíveis zigotos foram lavados em meio de cultivo, para que os espermatozoides aderidos fossem removidos, e, assim, os possíveis zigotos (30) foram transferidos para gotas de $200 \mu \mathrm{L}$ de meio CIV.

A taxa de clivagem foi avaliada após 72 horas do período de fecundação. Foram realizadas três repetições, sendo observados aproximadamente 32 ovócitos em cada grupo experimental a cada repetição

Um total de 833 ovócitos (quatro repetições, utilizando em média 52 ovócitos em cada grupo experimental a cada repetição) de grau I foram selecionados e distribuídos aleatoriamente em delineamento inteiramente ao acaso (DIC) nos referidos grupos experimentais. Os dados obtidos para as taxas de expansão do CCOs e de desenvolvimento embrionário foram arranjados em tabelas de contingência e analisados pelo teste de qui-quadrado $(\chi 2)$ com grau de liberdade igual a 1 (cada tratamento em relação ao grupo controle e entre tratamentos). Para a concentração de ROS, os dados foram testados para a normalidade e a homocedasticidade, seguidos de ANOVA, e as médias comparadas pelo teste de Duncan, empregando-se o programa estatístico SAEG 9,1 (Sistema..., 2007), com probabilidade de erro de $5 \%$.

\section{RESULTADOS}

$\mathrm{Na}$ avaliação da maturação ovocitária houve diferença $(\mathrm{P}<0,05)$ entre o grupo controle e os grupos $\mathrm{T} 1, \mathrm{~T} 2, \mathrm{~T} 3 \mathrm{em}$ relação ao grau de expansão 2 e 4 sendo que os grupos tratados obtiveram os melhores resultados já que apresentaram menor quantidade de ovócitos com expansão grau 2 e maior quantidade de ovócitos com expansão grau 4. Para o grau de expansão 4 não houve diferença $(\mathrm{P}>0,05)$ entre os grupos tratados, entretanto, para o grau de expansão 2 o grupo T2 apresentou menores quantidades $(\mathrm{P}<0,05)$ de ovócitos para este grau de expansão do que os demais grupos tratados (Tab. 1). Não foram observadas diferenças $(\mathrm{P}>0,05)$ no grau de expansão 3 entre os grupos e, também, não foram observados valores de expansão para as classificações zero e 1 entre os grupos. 
Adição da proteína...

Tabela 1. Adição da melatonina e proteína pOSP durante a maturação in vitro e seus efeitos na expansão das células do cumulus oophorus de ovócitos de porcas

\begin{tabular}{ccccc}
\hline Grupos & $N^{\mathrm{o}}$ de ovócitos & \multicolumn{4}{c}{ Grau de expansão do CCO n(\%) } \\
\hline Grupo C & $\mathbf{2}$ & $\mathbf{3}$ & $\mathbf{4}$ \\
\hline Grupo T1 & 215 & $77(40,0)^{\mathrm{a}}$ & $72(37,5)^{\mathrm{a}}$ & $43(22,5)^{\mathrm{b}}$ \\
Grupo T2 & 222 & $48(22,3)^{\mathrm{b}}$ & $83(38,6)^{\mathrm{a}}$ & $84(39,0)^{\mathrm{a}}$ \\
\hline Grupo T3 & 204 & $31(13,9)^{\mathrm{c}}$ & $88(39,6)^{\mathrm{a}}$ & $105(47,3)^{\mathrm{a}}$ \\
\hline
\end{tabular}

Zero = sem expansão das células do CCOs; 1 = mínimo de resposta observável; 2 = expansão das camadas mais externas do CCOs; 3 = expansão de todas as camadas, exceto a corona radiata e 4 = expansão de todas as camadas do CCOs. N (\%) número amostral e porcentagem. Médias seguidas de mesma letra minúscula não diferem entre si. Grupo C: meio MIV sem suplementação de melatonina e/ou pOSP; grupo T1: suplementação com melatonina na MIV; grupo T2: adição de melatonina na MIV e adição de pOSP nas quatro horas finais da maturação; grupo T3: adição de pOSP nas quatro horas finais da maturação.

Com relação ao ROS, não houve diferença $(\mathrm{P}>0,05)$ entre os valores de pixels obtidos nos grupos $\mathrm{C}$ e $\mathrm{T} 1$, porém o grupo $\mathrm{C}$ diferiu do valor obtido em T2 $(\mathrm{P}<0,05)$, sendo este considerado melhor do que o grupo C. No entanto, os valores médios obtidos em T3 mostraram melhores resultados $(\mathrm{P}<0,05)$ quando comparados aos dos demais tratamentos (Tab. 2).

Tabela 2. Valores médios e desvios-padrão para a concentração de espécies reativas de oxigênio em ovócitos de porcas maturados in vitro com adição de melatonina e proteína específica do oviduto (pOSP) aos meios de maturação. Médias seguidas por letras diferentes na mesma coluna diferem entre si $(\mathrm{P}<0,05)$ pelo teste de Duncan

\begin{tabular}{lcc}
\hline Grupos & $N^{\mathrm{o}}$ de ovócitos & $\begin{array}{c}\text { Dosagem de } \\
\text { ROS }\end{array}$ \\
\hline Grupo C & 35 & $26,4 \pm 10,9^{\mathrm{a}}$ \\
Grupo T1 & 34 & $23,4 \pm 7,8^{\mathrm{ab}}$ \\
Grupo T2 & 33 & $21,3 \pm 9,7^{\mathrm{b}}$ \\
Grupo T3 & 41 & $16,6 \pm 10,5^{\mathrm{c}}$ \\
\hline Grupo C: meio MIV sem suplementação de \\
melatonina e/ou pOSP; grupo T1: suplementação com \\
melatonina na MIV; grupo T2: adição de melatonina \\
na MIV e adição de pOSP nas quatro horas finais da \\
maturação; grupo T3: adição de pOSP nas quatro \\
horas finais da maturação.
\end{tabular}

$\mathrm{Na}$ taxa de clivagem, não houve diferença $(\mathrm{P}>0,05)$ entre os valores médios obtidos no grupo C $(48,9 \%)$ e nos grupos T1 $(51,5 \%)$, T2 $(50 \%)$ e $\mathrm{T} 3(57,7 \%)$ nem destes entre si (Tab. 3).
Tabela 3. Adição da melatonina e proteína específica do oviduto (pOSP) durante a maturação in vitro e seus efeitos na taxa de clivagem de embriões de porcas

\begin{tabular}{lcc}
\hline Grupos & $\mathrm{N}^{0}$ de ovócitos & $\begin{array}{c}\text { Taxa de } \\
\text { clivagem (\%) }\end{array}$ \\
\hline Grupo C & 137 & 48,9 \\
Grupo T1 & 128 & 51,5 \\
Grupo T2 & 130 & 50,0 \\
Grupo T3 & 123 & 57,7 \\
\hline Grupo C: meio MIV sem suplementação de \\
melatonina e/ou pOSP; grupo T1: suplementação com \\
melatonina na MIV; grupo T2: adição de melatonina \\
na MIV e adição de pOSP nas quatro horas finais da \\
maturação; grupo T3: adição de pOSP nas quatro \\
horas finais da maturação.
\end{tabular}

\section{DISCUSSÃO}

O presente estudo demonstrou que a melatonina in vitro utilizada na concentração de $10^{-9} \mathrm{M}$ melhorou a expansão do CCOs. Isso pode ser explicado porque a melatonina desempenha papel na regulação da maturação do ovócito de diversas espécies, como em suínos, bubalinos, ovinos e bovinos (Kang et al., 2009; Manjunatha et al., 2009; Casão et al., 2010; El-Raey et al., 2011). No cultivo de ovócitos bovinos, a suplementação com melatonina em concentrações de $4 \times 10^{-8} \mathrm{M}$ ou $2 \times 10^{-7} \mathrm{M}$ durante a maturação in vitro promoveu aumento na taxa de maturação nuclear e na taxa de ovócitos com mitocôndrias dispersas no citoplasma, bem como melhorou a expansão do CCOs (El-Raey et al., 2011). Além disso, melhorou a maturação citoplasmática de ovócitos suínos (RodriguezOsorio et al., 2007) e o desenvolvimento 
embrionário in vitro de ovinos (Abecia et al., 2002). Entretanto, nos estudos realizados por Nakano et al. (2012), os autores verificaram que a adição de melatonina nos meios de maturação de ovócitos de suínos por $40 \mathrm{~h}$, na concentração de $10^{-7} \mathrm{M}$, não aumentou as taxas de maturação dos ovócitos (53-60 versus 65 e 69\%) nem o potencial de ovócitos para se desenvolverem a blastocistos após ativação partenogenética.

No presente estudo, a pOSP melhorou a expansão do CCOs provavelmente por auxiliar na maturação ovocitária final, já que, in vivo, o oviduto é responsável também pela maturação, conforme pressuposto pelos autores Buhi e Alvarez (2003); Mccauley et al. (2003) e Janjanam et al. (2012). No entanto, a associação da melatonina com a pOSP não apresentou maior quantidade de ovócitos com expansão grau 4 quando comparado aos outros grupos tratados (T1 e T3), mas teve menor quantidade de ovócitos com grau de expansão 2 mostrando efeito positivo deste tratamento sobre a expansão das células do cumulus.

Durante a produção in vitro de embriões, as espécies reativas de oxigênio são produzidas e podem causar danos oxidativos graves, resultando em menor taxa de produção de blastocistos. A melatonina e seus metabólitos são antioxidantes eficazes, que neutralizam ROS e regulam várias enzimas antioxidantes (Tan et al., 2007). A suplementação com melatonina nos meios de maturação diminuiu o ROS (Nakano et al., 2012) e melhorou o desenvolvimento dos ovócitos de suínos (Kang et al., 2009; Shi et al., 2009). Em bubalinos, houve redução do estresse oxidativo, da concentração de ROS e danos ao DNA quando a melatonina foi adicionada aos meios de maturação (Manjunatha et al., 2009).

Entretanto, em relação a menores quantidades de ROS produzidos pelos ovócitos, no presente estudo, o tratamento com a melatonina mostrouse ineficaz quando comparado ao controle e aos demais tratamentos. Isto pode ser explicado porque o experimento foi realizado no período de verão, o que poderia ter piorado a qualidade dos ovócitos, e a melatonina, nessas condições, não era o antioxidante mais eficaz na diminuição de ROS. Além disso, a concentração de melatonina utilizada pode não ter sido a mais adequada, sendo necessárias concentrações mais elevadas, devido a condições ambientais e de cultivo do presente estudo.

Quando a melatonina foi associada à pOSP, houve redução da quantidade de ROS, mostrando melhores resultados em relação ao controle. Porém, este resultado foi inferior quando comparado ao tratamento com pOSP isolada. Tal fato revelou que as condições em que a melatonina foi utilizada não foram as melhores para ela atuar na redução de ROS, como visto anteriormente, e que isto poderia ter levado a certos prejuízos, pois quando a pOSP foi utilizada isoladamente, houve redução de ROS em relação aos grupos que utilizaram melatonina, mostrando a pOSP como um antioxidante proteico mais eficaz que a melatonina, no presente estudo. Esse resultado, possivelmente, demonstra um efeito positivo da pOSP propiciando melhores condições para o ovócito. In vivo, isso seria ocasionado durante o período após a ovulação e antes da fecundação, momento este em que o óvulo se encontra no oviduto e está sujeito às ações benéficas da pOSP.

Comparações entre qualidade de ovócitos maturados in vivo e in vitro são discutidas na literatura (Yuan et al., 2012), indicando que as condições in vitro não são favoráveis para o cultivo. Nesse sentido, a suplementação do meio de maturação com substâncias que melhorem a qualidade dos ovócitos necessita ser mais investigada. Assim, a melatonina e a pOSP têm grande potencial de serem utilizadas, já que podem apresentar vantagens, como a melhora da expansão do complexo cumulus-ovócito e a diminuição da quantidade de ROS.

A pOSP poderia atuar, então, como um antioxidante proteico ou poderia agir pelo aumento da expressão de enzimas antioxidantes benéficas para o desenvolvimento do ovócito. Entretanto, mais pesquisas são necessárias a fím de se caracterizar a estrutura da proteína e se determinarem os possíveis locais que seriam responsáveis pela função antioxidante, além de se analisar a expressão das enzimas antioxidantes durante a maturação do ovócito suíno.

No presente estudo, por mais que a melatonina tenha ocasionado melhor expansão do CCOs, ela não se mostrou eficaz em reduzir as espécies reativas de oxigênio e, por isso, pode não ter 
proporcionado os melhores índices de clivagem embrionária. Nos estudos de Kang et al. (2009) utilizando a melatonina na concentração de $4 \times 10^{-}$

${ }^{8} \mathrm{M}$ durante a maturação in vitro, apesar de resultar em maior percentual de extrusão do corpúsculo polar, a taxa de clivagem e o número de células por blastocisto não foram afetados. A taxa de clivagem também não se mostrou melhor quando a pOSP foi adicionada aos meios, como também verificado por Kouba et al. (2000). Possivelmente, devido ao fato de as condições in vitro serem inadequadas, seriam necessárias maiores quantidades de pOSP no ambiente in vitro para ter-se efeito em relação à taxa de clivagem.

\section{CONCLUSÕES}

Este é o primeiro relato de que a proteína específica do oviduto (pOSP) pode apresentar uma possível função antioxidante, sendo necessários mais estudos, a fim de se verificarem outras possíveis funções da proteína. Além disso, o presente estudo conclui que a melatonina e a proteína específica do oviduto (pOSP) são eficientes em melhorar a expansão do complexo cumulus-ovócito (CCOs) de suínos, porém não se mostram eficazes em aumentar a taxa de clivagem durante a produção in vitro de embriões.

\section{AGRADECIMENTOS}

Aos funcionários do frigorífico Saudali, Ponte Nova, Brasil, por cederem os ovários suínos; à Capes, à Fapemig e ao CNPq, pelo apoio concedido.

\section{REFERÊNCIAS}

ABECIA, J.A.; FORCADA, F.; ZÚNIGA, O. The effect of melatonin on the secretion of progesterone in sheep and on the development of ovine embryos in vitro. Vet. Res. Commun., v.26, p.151-158, 2002.

ABEYDEERA, L.R.; DAY, B.N. Fertilization and subsequent development in vitro of pig oocytes inseminated in a modified tris-buffered medium with frozen-thawed ejaculated spermatozoa. Biol. Reprod., v.57, p.729-734, 1997.
AGARWAL, A.; DURAIRAJANAYAGAM, D.; PLESSIS, S.S. Utility of antioxidants during assisted reproductive techniques: an evidence based review. Reprod. Biol. Endocrinol., v.12, p.112, 2014.

BUHI, W.C. Characterization and biological roles of oviduct-specific, oestrogen-dependent glycoprotein. Reproduction, v.123, p.355-362, 2002.

BUHI, W.C.; ALVAREZ, I.M. Identification, characterization and localization of three proteins expressed by the porcine oviduct. Theriogenology, v.60, p.225-238, 2003.

CASAO, A.; ABECIA, J.A.; CEBRIAN PEREZ, J.A. et al. The effects of melatonin on in vitro oocyte competence and embryo development in sheep. Span. J. Agric. Res., v.8, p.35-41, 2010.

CEBRIAN-SERRANO, A.; SALVADOR, I.; GARCÍA-ROSELLO, E. et al. Effect of the bovine oviductal fluid on in vitro fertilization, development and gene expression of in vitroproduced bovine blastocysts. Reprod. Domest. Anim., v.48, p.331-338, 2013.

CETICA, P.D.; PINTOS, L.N.; DALVIT, G.C.; BECONI, M.T. Antioxidant enzyme activity and oxidative stress in bovine oocyte in vitro maturation. Int. Union Biochem. Mol. Biol. Life, v.51, p.57-64, 2001.

COY, P.; CANOVAS, D.; MONDEJAR, I. et al. Oviduct-specific glycoprotein and heparin modulate sperm-zona pellucida interaction during fertilization and contribute to the control of polyspermy. Proc. Natl. Acad. Sci., v.105, p.15809-15814, 2008.

DO, L.T.K.; SHIBATA, Y.; TANIGUCHI, M. et al. Melatonin supplementation during in vitro maturation and development supports the development of porcine embryos. Reprod. Domest. Anim., v.50, p.1054-1058, 2015.

EL-RAEY, M.; GESHI, M.; SOMFAI, T. et al. Evidence of melatonin synthesis in the cumulus oocyte complexes and its role in enhancing oocyte maturation in vitro in cattle. Mol. Reprod. Dev., v.78, p.250-262, 2011.

GOMEZ, M.N.; KANG, J.T.; KOO, O.J. et al. Effect of oocyte-secreted factors on porcine in vitro maturation, cumulus expansion and developmental competence of parthenotes. Zygote, v.20, p.135-45, 2012. 
HASHIMOTO, S.; MINAMI, N.; YAMADA, M.; IMAI, H. Excessive concentration of glucose during in vitro maturation impairs the developmental competence of bovine oocyte after in vitro fertilization: relevance to intracellular reactive oxygen species and glutathione contents. Mol. Reprod. Dev., v.55, p.520-526, 2000.

JANJANAM, J.; SINGH, S.; CHOUDHARY, S. et al. Molecular cloning, sequence characterization and heterologous expression of buffalo (Bubalus bubalis) oviduct - specific glycoprotein in E. coli. Mol. Biol. Reprod., v.39, p.10031-10043, 2012.

KANG, J.T.; KOO, O.J.; KWON, D.K. et al. Effects of melatonin on in vitro maturation of porcine oocyte and expression of melatonin receptor RNA in cumulus and granulose cells. $J$. Pineal. Res., v.46, p.22-28, 2009.

KOUBA, A.J.; ABEYDEERA, L.R.; ALVAREZ, I.M. et al. Effects of the porcine oviduct-specific glycoprotein on fertilization, polyspermy, and embryonic development in vitro. Biol. Reprod., v.63, p.242-250, 2000.

KWAK, S.S.; JEUNG, S.H.; BISWAS, D. et al. Effects of porcine granulocyte-macrophage colony-stimulating factor on porcine in vitrofertilized embryos. Theriogenology, v.77, p.1186-1197, 2012.

MANJUNATHA, B.M.; DEVARAJ, M.; GUPTA, P.S.P. et al. Effect of taurine and melatonin in the culture medium on buffalo in vitro embryo development. Reprod. Domest. Anim., v.44, p.12-16, 2009.

MCCAULEY, T.C.; BUHI, W.C.; WU, G.M. et al. Oviduct-specific glycoprotein modulates sperm-zona binding and improves efficiency of porcine fertilization in vitro. Biol. Reprod., v.69, p.828-834, 2003.

MIESSEN, K.; SHARBATI, S.; EINSPANIER, R. et al. Modelling the porcine oviduct epithelium: a polarized in vitro system suitable for long-term cultivation. Theriogenology, v.76, p.900-910, 2011.
MONDÉJAR, I.; MARTÍNEZ-MARTÍNEZ, I.; AVILÉS, M.; COY, P. Identification of potential oviductal factors responsible for zona pellucida hardening and monospermy during fertilization in mammals. Biol. Reprod., v.89, p.67, 2013.

NAKANO, M.; KATO, Y.; TSUNODA, Y. Effect of melatonin treatment on the developmental potential of parthenogenetic and somatic cell nuclear-transferred porcine oocytes in vitro. Zygote, v.20, p.199-207, 2012.

PETTERS, R.M.; WELLS, K.D. Culture of pig embryos. J. Reprod. Fertil., v.48, p.61-73, 1993.

RODRIGUEZ-OSORIO, N.; KIM, I.J.; WANG, $\mathrm{H}$. Melatonin increases cleavage rate of porcine preimplantation embryos in vitro. J. Pineal. Res., v.43, p.283-288, 2007.

ROMAR, R.; FUNAHASHI, H.; COY, P. In vitro fertilization in pigs: new molecules and protocols to consider in the forthcoming years. Theriogenology, v.85, p.125-134, 2015.

SHI, J.M.; TIAN, X.Z.; ZHOU, G.B. et al. Melatonin exists in porcine follicular fluid and improves in vitro maturation and parthenogenetic development of porcine oocytes. J. Pineal. Res., v.47, p.318-323, 2009

SISTEMA para análises estatísticas - SAEG. Versão 9.1. Viçosa: UFV, Fundação Arthur Bernardes, 2007. 142p.

TAKAHASHI, M. Oxidative stress and redox regulation on in vitro development of mammalian embryos. J. Reprod. Dev., v.58, p.19, 2012

TAN, D.X.; MANCHESTER, L.C.; TERRON, M.P. et al. One molecule, many derivatives: a never-ending interaction of melatonin with reactive oxygen and nitrogen species. J. Pineal. Res., v.42, p.28-42, 2007.

WONGSRIKEAO, P.; OTOI, T.; TANIGUCHI, M. et al. Effects of hexoses on in vitro oocyte maturation and embryo development in pigs. Theriogenology, v.65, p.332-343, 2006.

YUAN, Y.; WHEELER, M.B.; KRISHER, R.L. Disrupted redox homeostasis and aberrant redox gene expression in porcine oocytes contribute to decreased developmental competence. Biol. Reprod., v.87, p.78, 2012. 